\title{
Bismuth-Catalyzed Benzylic Oxidations with tert-Butyl Hydroperoxide
}

Yannick Bonvin, ${ }^{\dagger}$ Emmanuel Callens, ${ }^{\dagger}$ Igor Larrosa, ${ }^{\dagger}$ David A. Henderson, ${ }^{\dagger}$ James Oldham, $^{\dagger}{ }^{\text {Andrew J. Burton }}{ }^{\ddagger}$ and Anthony G. M. Barrett ${ }^{\dagger *}$

Department of Chemistry, Imperial College London, Exhibition Road, London SW7 2AZ, England, and Synthetic Chemistry, GlaxoSmithKline, Medicines Research Centre, Stevenage SG1 2NY, England.

agmb@imperial.ac.uk

\section{Experimental}

Proton magnetic resonance spectra $\left({ }^{1} \mathrm{H}\right.$ NMR) were recorded at $300 \mathrm{MHz}$. Chemical shifts $(\delta)$ are quoted in parts per million (ppm) and are referenced to the residual solvent peak, 7.26 for $\mathrm{CDCl}_{3}$, and 2.52 for DMSO- $\mathrm{d}_{6}$. Carbon magnetic resonance spectra $\left({ }^{13} \mathrm{C} \mathrm{NMR}\right)$ were recorded at 75 MHz. Chemical shifts $(\delta)$ are quoted in parts per million (ppm) and are referenced to the residual solvent peak, 77.0 for $\mathrm{CDCl}_{3}$ and 39.7 for DMSO- $\mathrm{d}_{6}$. Coupling constants $(\mathrm{J})$ are quoted in Hertz (Hz) for both ${ }^{1} \mathrm{H}$ and ${ }^{13} \mathrm{C}$ NMR. The following abbreviations were used to explain the multiplicities: $\mathrm{s}=$ singlet, $\mathrm{d}=$ doublet, $\mathrm{dq}=$ doublet of quartets, $\mathrm{t}=$ triplet, $\mathrm{dt}=$ doublet of triplets, $\mathrm{q}=$ quartet, $\mathrm{m}=$ multiplet. Reactions were monitored by Gas Chromatography Mass spectrometry. 


\section{General procedure for the oxidation of alkylarenes to ketones:}

$\mathrm{NaBH}_{4}(18 \mathrm{mg}, 0.48 \mathrm{mmol})$ was added with vigorous stirring to a suspension of $\mathrm{Bi}_{2} \mathrm{O}_{3}(37 \mathrm{mg}$, $0.08 \mathrm{mmol})$ in distilled $\mathrm{H}_{2} \mathrm{O}(1.5 \mathrm{~mL})$ at room temperature giving a finely divided, black precipitate of bismuth metal. This was washed with $\mathrm{H}_{2} \mathrm{O}(2 \times 2 \mathrm{~mL})$, when pyridine $(0.8 \mathrm{~mL})$, AcOH $(0.08 \mathrm{~mL})$, picolinic acid $(20 \mathrm{mg}, 0.16 \mathrm{mmol})$, substrate $(0.8 \mathrm{mmol})$ and $t$ - $\mathrm{BuOOH}$ in $\mathrm{H}_{2} \mathrm{O}$ (70\%; $0.66 \mathrm{~mL}, 4.8 \mathrm{mmol}$ ) were added. The mixture was sonicated for $30 \mathrm{~min}$ and heated at 100 ${ }^{\circ} \mathrm{C}$ for $16 \mathrm{~h}$ (sealed vessel), cooled, diluted with $\mathrm{CH}_{2} \mathrm{Cl}_{2}$, filtered through Celite ${ }^{\circledR}$ and rotary evaporated. The resulting oil was analyzed by NMR and GCMS and subsequently chromatographed to yield the corresponding ketone.

Ketones obtained are all known compounds, which are commercially available or previously described. Their analytical data are similar with those reported in the literature.

\section{General procedure for the oxidation of methylarenes to arenecarboxylic acids:}

A suspension of $\mathrm{Bi}(\mathrm{OTf})_{3}(105 \mathrm{mg}, 0.16 \mathrm{mmol})$, pyridine $(0.8 \mathrm{~mL}), \mathrm{AcOH}(0.13 \mathrm{~mL})$, picolinic acid $(10 \mathrm{mg}, 0.08 \mathrm{mmol})$, substrate $(0.8 \mathrm{mmol})$ and $t$-BuOOH in $\mathrm{H} 2 \mathrm{O}(70 \%$; $0.77 \mathrm{~mL}, 5.6 \mathrm{mmol})$ was sonicated for $30 \mathrm{~min}$ and then heated at $110^{\circ} \mathrm{C}$ for $20 \mathrm{~h}$ (sealed vessel). After cooling, EtOAc was added and the resulting suspension was washed with aqueous $\mathrm{HCl}(10 \% ; 10 \mathrm{~mL})$ and brine $(10 \mathrm{~mL})$. The organic layer was dried $\left(\mathrm{MgSO}_{4}\right)$, rotary evaporated and the resulting oil was analyzed (NMR and GCMS) and subsequently chromatographed to yield the corresponding carboxylic acid, which were commercially available and showed ${ }^{1} \mathrm{H}$ and ${ }^{13} \mathrm{C}$ NMR spectra and mp identical with data reported except for 4-Bromo-naphthalene-1-carboxylic acid. 


\section{4-Bromo-naphthalene-1-carboxylic acid}

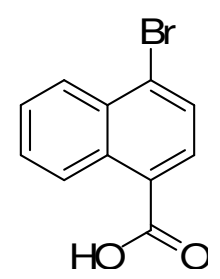

[recrystallised from EtOAc/Hexane] Mp 215-218 ${ }^{\circ} \mathrm{C}$ ( $\operatorname{ref}^{1} 217-220{ }^{\circ} \mathrm{C}$ ). IR (film) 3056-2875, 1696, 1279, 1252, $762 \mathrm{~cm}^{-1} .{ }^{1} \mathrm{H}$ NMR (DMSO, $\left.300 \mathrm{MHz}\right) \delta 7.77$ (m, 2H), $8.00(\mathrm{~m}, 2 \mathrm{H}), 8.25(\mathrm{~m}$, $1 \mathrm{H}), 8.91(\mathrm{~m}, 1 \mathrm{H}), 13.43(\mathrm{~s}, 1 \mathrm{H}) \mathrm{ppm} .{ }^{13} \mathrm{C}$ NMR (DMSO, $\left.75 \mathrm{MHz}\right) \delta 126.2,126.8,126.9$, $128.0,128.3,128.4,129.3,129.9,131.3,131.7,168.0 \mathrm{ppm}$. MS (CI+) $\mathrm{m} / z 250(\mathrm{M}+\mathrm{H})^{+}, 268$ $\left(\mathrm{M}+\mathrm{NH}_{4}\right)^{+}$. HRMS calc for $\mathrm{C}_{11} \mathrm{H}_{11} \mathrm{BrNO}_{2}:\left(\mathrm{M}+\mathrm{NH}_{4}\right)^{+}, 267.9963$, found: $\left(\mathrm{M}+\mathrm{NH}_{4}\right)^{+}$, 267.9973. Anal. calc. for $\mathrm{C}_{11} \mathrm{H}_{7} \mathrm{BrO}_{2}$ : C, 52.62, $\mathrm{H}, 2.81$. Found: C, 52.55; H, 2.95.

\footnotetext{
${ }^{1}$ Bichan, D. J.; Yates, P. Can. J. Chem. 1975, 53, 2054-2063.
} 
<smiles>CC(=O)c1cccc(Br)c1</smiles>

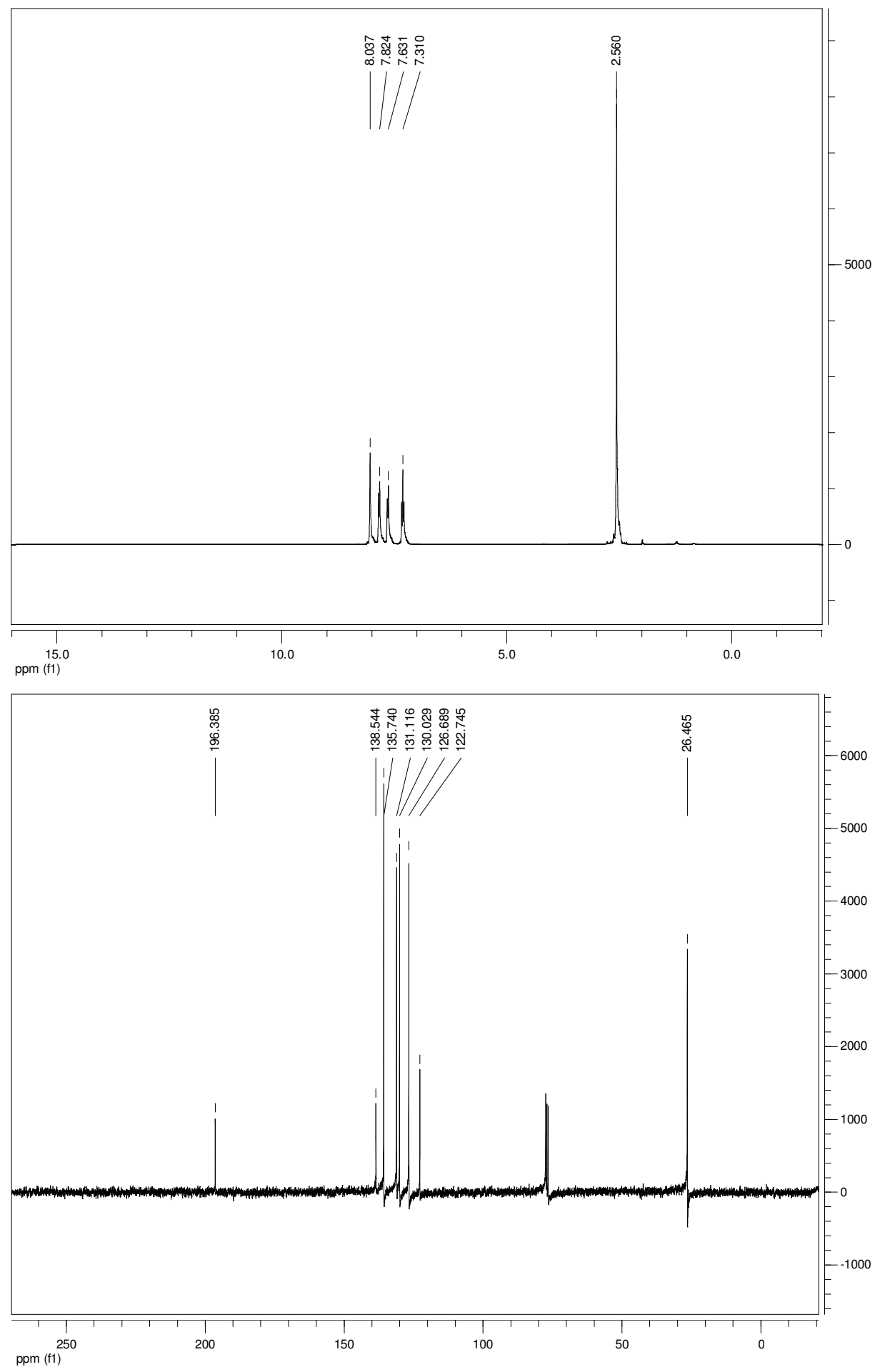


<smiles>CCCC(=O)c1cccnc1</smiles>

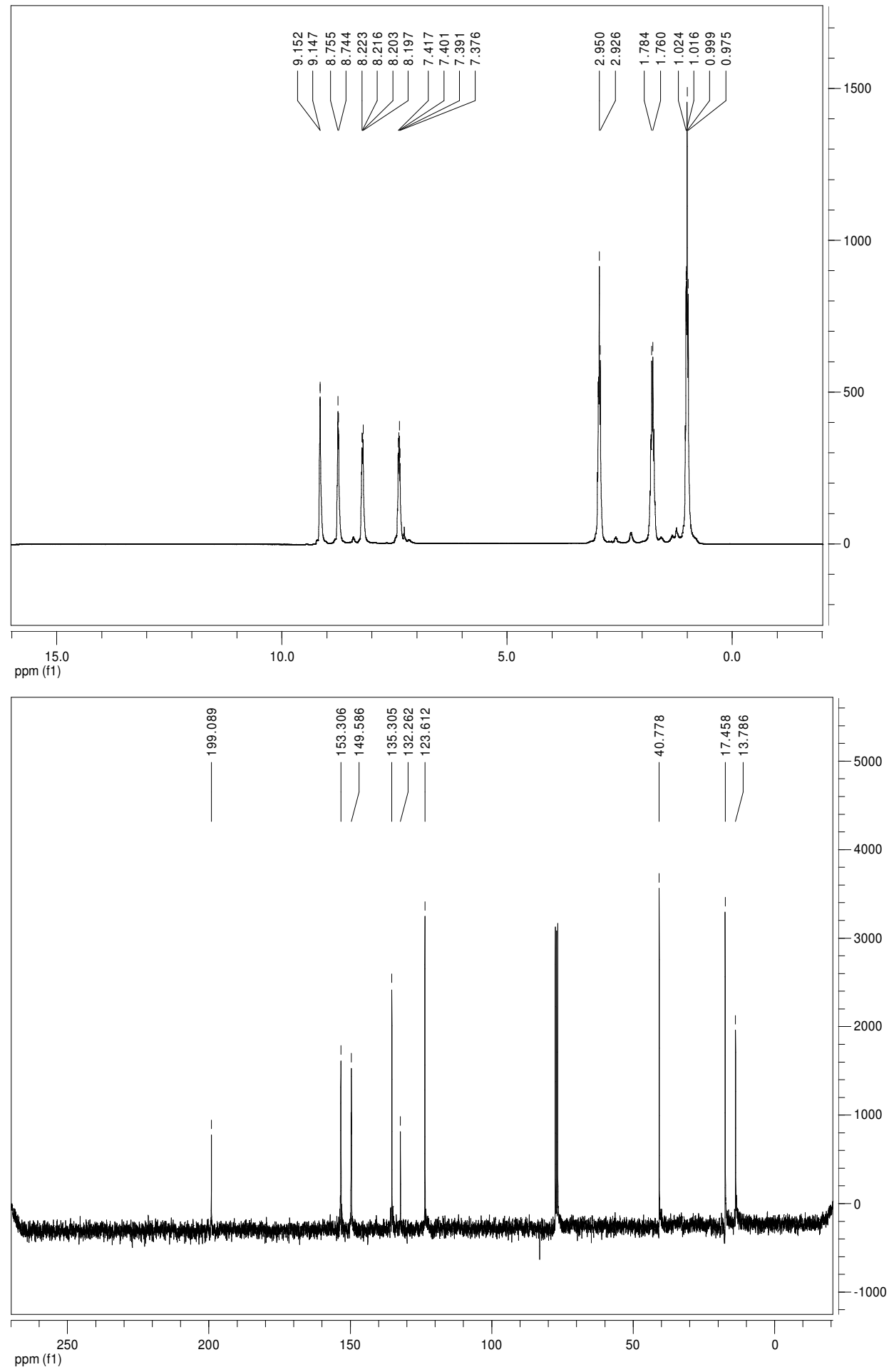


<smiles>C=C(C)N1CCC(=O)c2ccccc21</smiles>
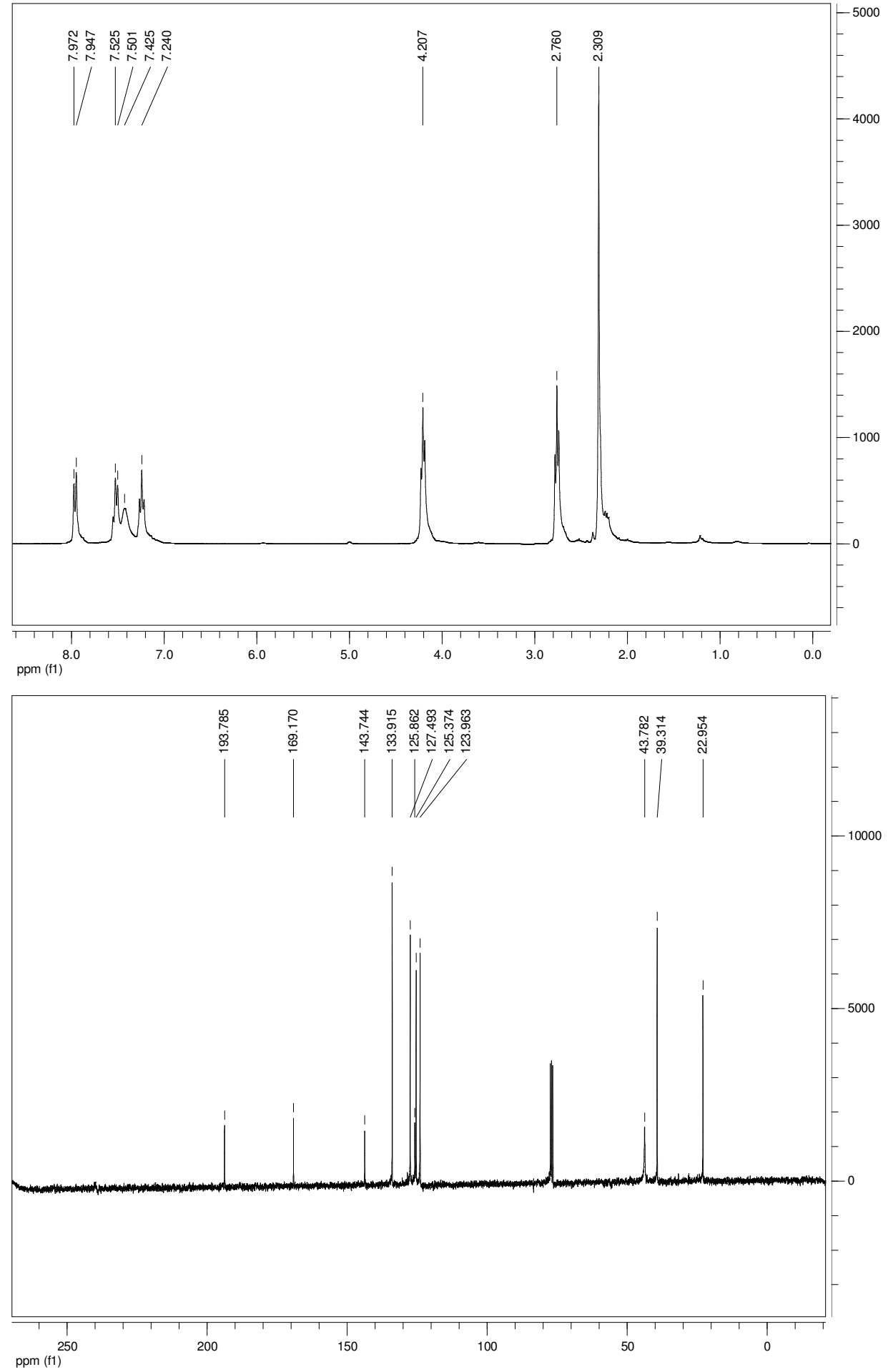


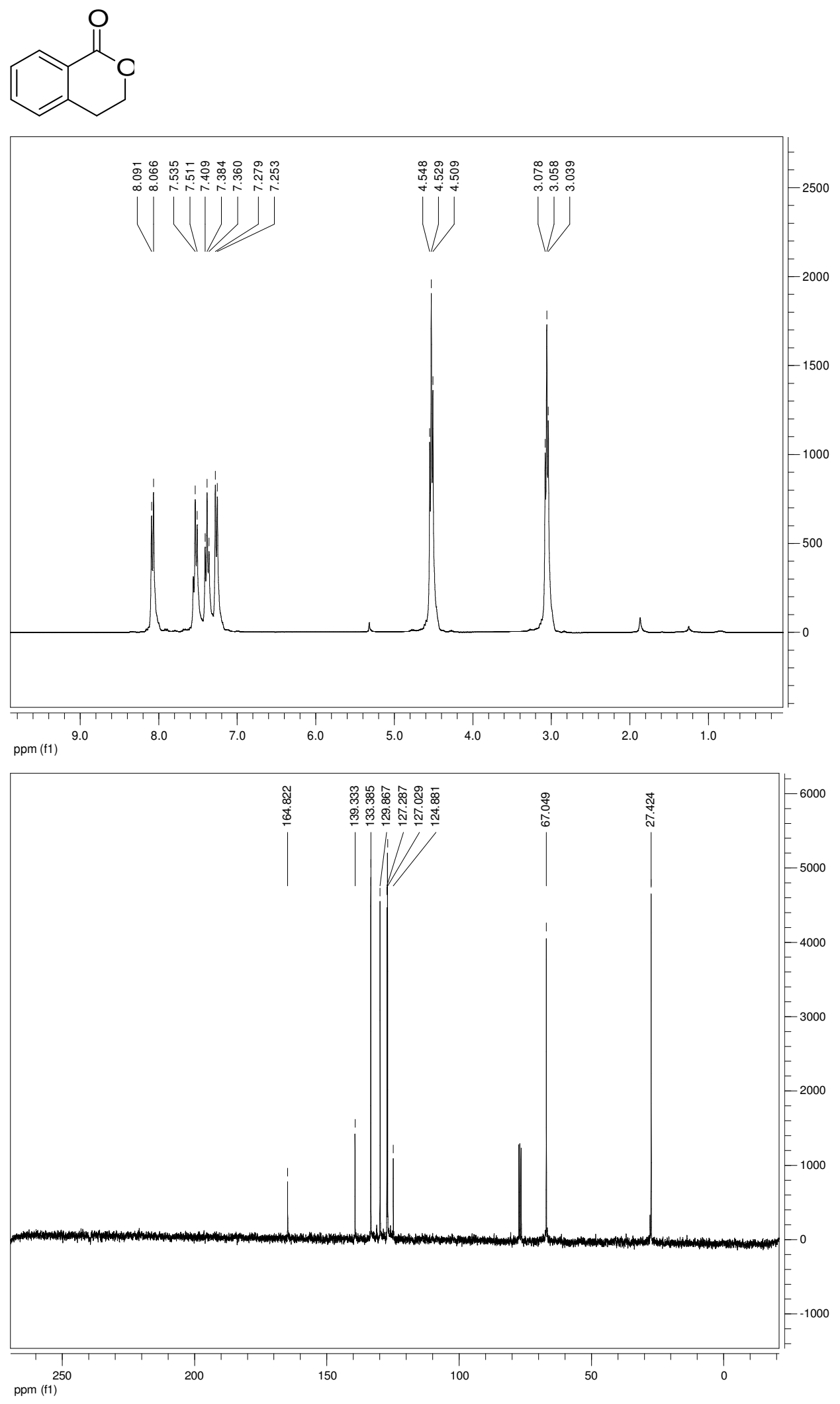


<smiles>Cc1cc(C)c(C(=O)O)cc1C</smiles>

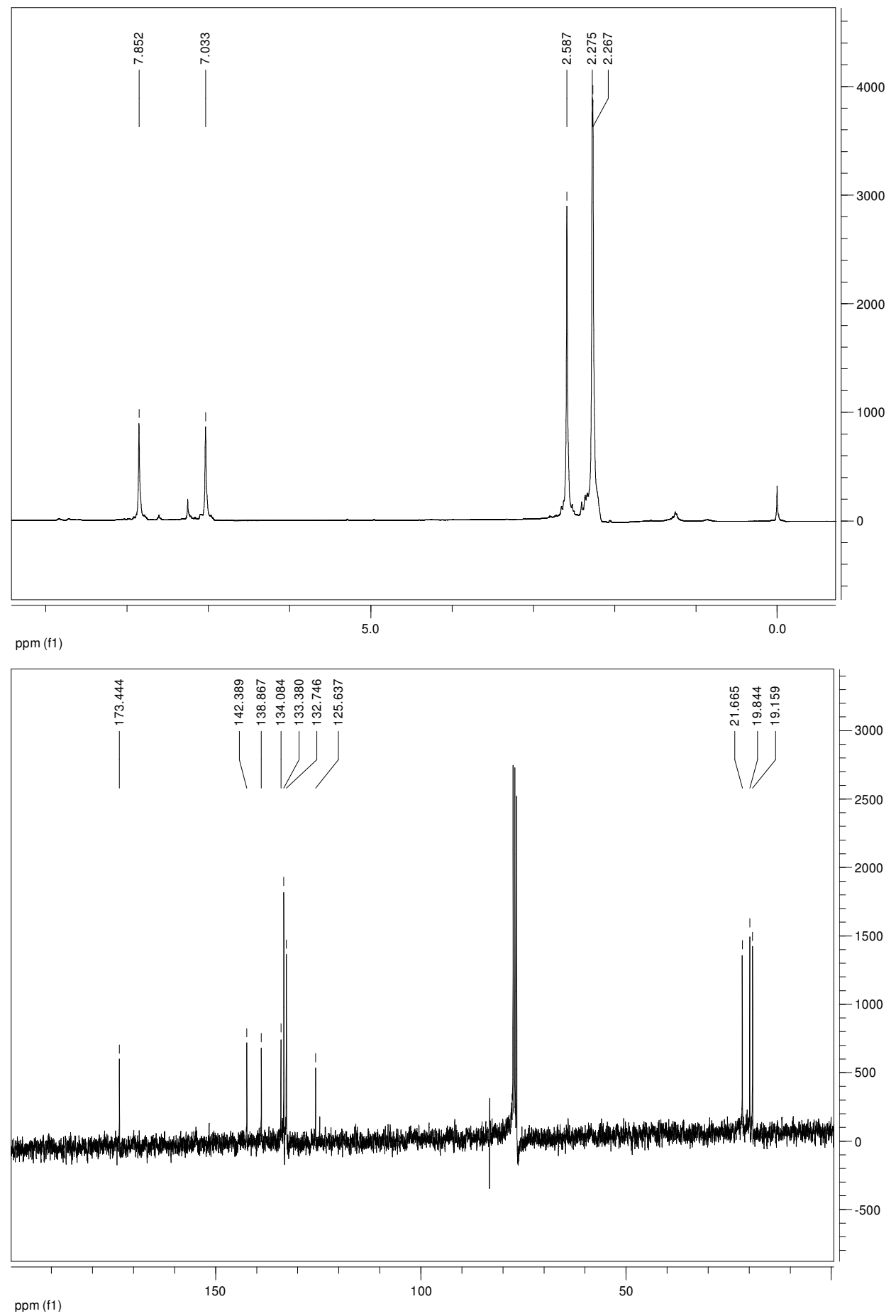




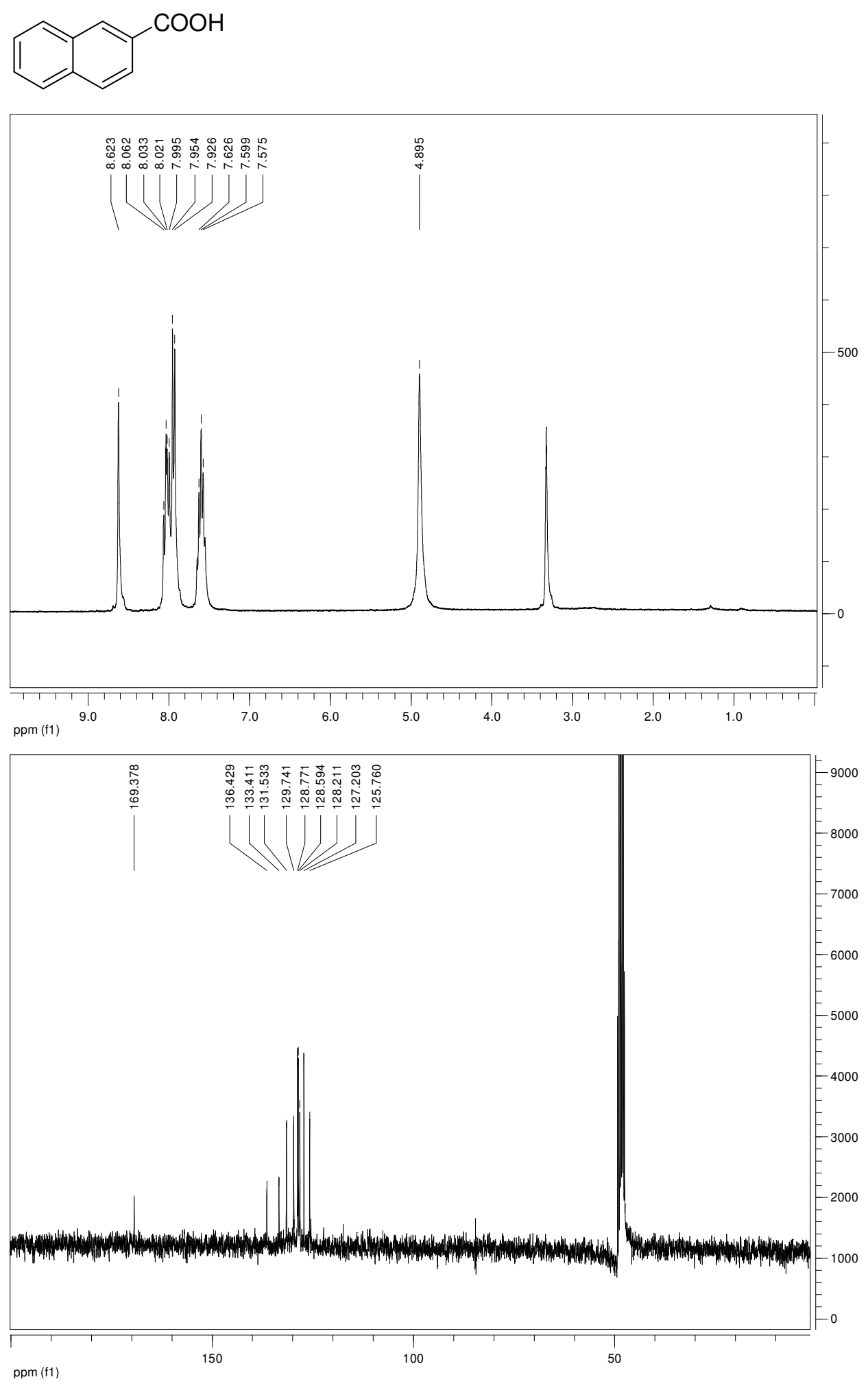



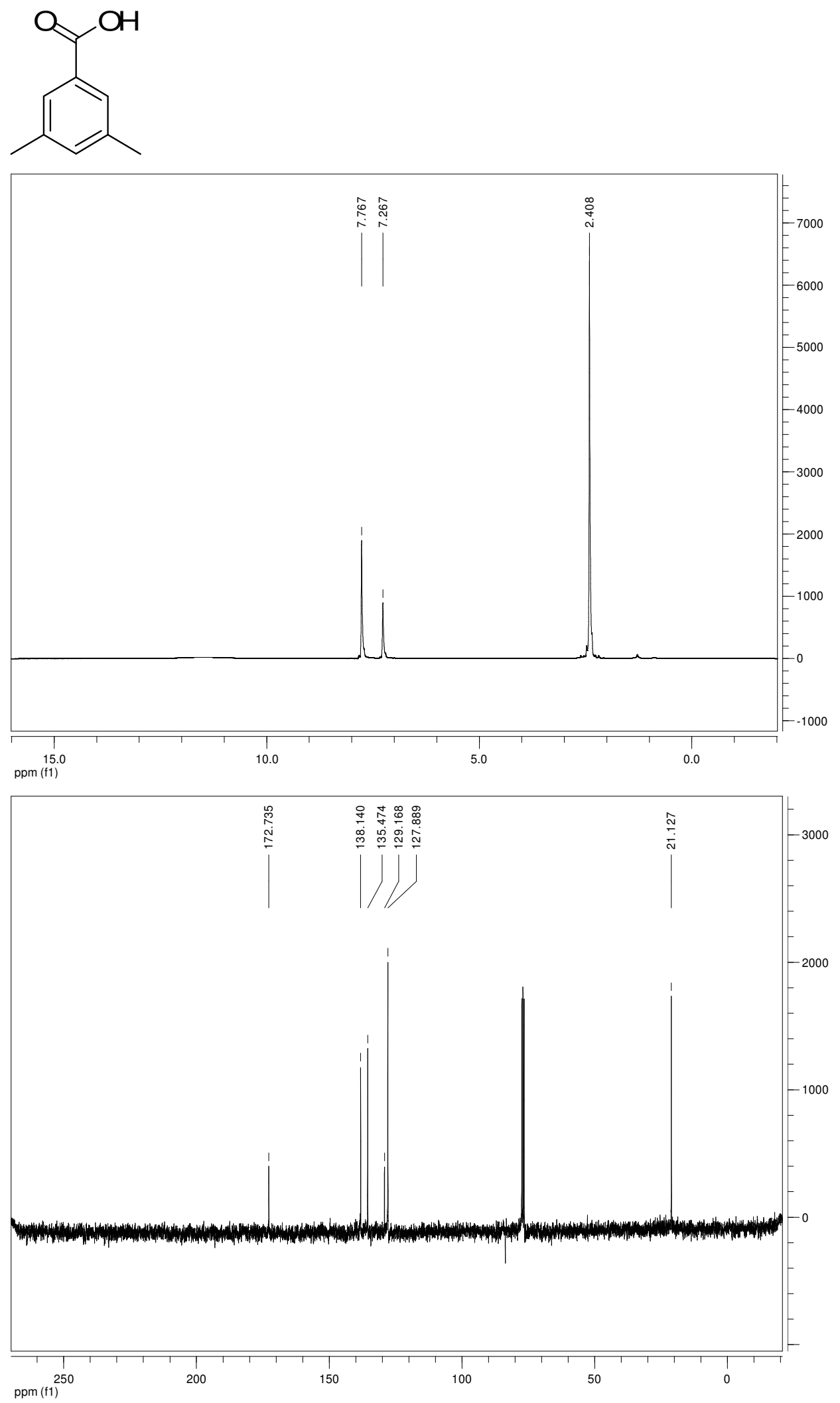
<smiles>C=C(O)c1ccc(Br)c2ccccc12</smiles>
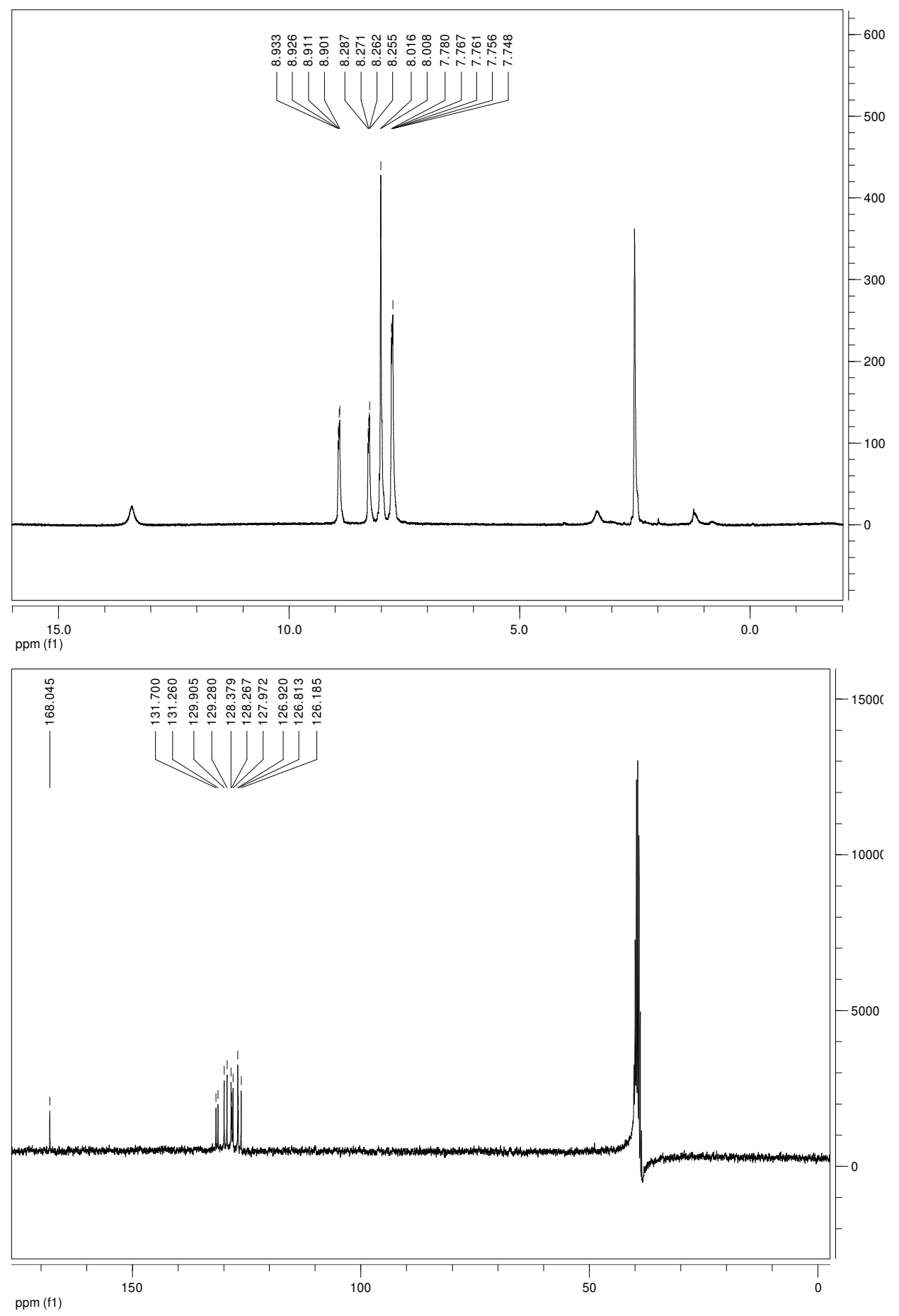